ARTICLE

DOI: $10.1057 /$ s41599-018-0154-0

\title{
Steps to improve gender diversity in coastal geoscience and engineering
}

\author{
Ana Vila-Concejo (1) et al. ${ }^{\#}$
}

\begin{abstract}
Robust data are the base of effective gender diversity policy. Evidence shows that gender inequality is still pervasive in science, technology, engineering and mathematics (STEM). Coastal geoscience and engineering (CGE) encompasses professionals working on coastal processes, integrating expertise across physics, geomorphology, engineering, planning and management. The article presents novel results of gender inequality and experiences of gender bias in CGE, and proposes practical steps to address it. It analyses the gender representation in 9 societies, 25 journals, and 10 conferences in CGE and establishes that women represent $30 \%$ of the international CGE community, yet there is underrepresentation in prestige roles such as journal editorial board members (15\% women) and conference organisers ( $18 \%$ women). The data show that female underrepresentation is less prominent when the path to prestige roles is clearly outlined and candidates can selfnominate or volunteer instead of the traditional invitation-only pathway. By analysing the views of 314 survey respondents (34\% male, 65\% female, and 1\% "other"), we show that $81 \%$ perceive the lack of female role models as a key hurdle for gender equity, and a significantly larger proportion of females (47\%) felt held back in their careers due to their gender in comparison with males (9\%). The lack of women in prestige roles and senior positions contributes to $81 \%$ of survey respondents perceiving the lack of female role models in CGE as a key hurdle for gender equality. While it is clear that having more women as role models is important, this is not enough to effect change. Here seven practical steps towards achieving gender equity in CGE are presented: (1) Advocate for more women in prestige roles; (2) Promote high-achieving females; (3) Create awareness of gender bias; (4) Speak up; (5) Get better support for return to work; (6) Redefine success; and, (7) Encourage more women to enter the discipline at a young age. Some of these steps can be successfully implemented immediately (steps 1-4), while others need institutional engagement and represent major societal overhauls. In any case, these seven practical steps require actions that can start immediately.
\end{abstract}




\section{Introduction}

ender diversity enhances scientific discovery and innovation (Nielsen et al., 2017), and leads to happier work places (Holter, 2014). However, the proportion of women researchers continues to be lower than men's, particularly in science, technology, engineering and mathematics (STEM). Globally, women represent $53 \%$ of science Bachelors and Master's students, $43 \%$ of Ph.D graduates, yet only $28-30 \%$ of researchers (Huyer, 2015). The issue of gender inequality and inequity in STEM has been raised for more than a century (Talbot, 1910); however, according to the editors of Nature News, women remain underrepresented (2017), particularly in senior positions (2013). In the USA, women hold $<13 \%$ of full professorial positions in the geosciences, despite being awarded $40 \%$ of doctoral degrees (Holmes et al., 2015). In Europe in 2013, science and technology women represented, respectively, $34 \%$ and $37 \%$ of doctoral students, 33\% of fixed-term academic staff (fixed-term lectureship/ postdoctoral researcher), $24 \%$ of tenured academics, and only $13 \%$ of full professors or equivalent (European Comission, 2016). Barriers to career progression of women in STEM include bias towards males for job positions (Dutt et al., 2016), higher salaries for men (Moss-Racusin et al., 2012), and a reduced likelihood of mentoring (Moss-Racusin et al., 2012). Although recent publications demonstrate that gender inequality in STEM is still prevalent (e.g., Miller and Wai 2015; Lerback and Hanson, 2017), there is little data on the underrepresentation in prestige roles in professional societies, journals or conference organising committees.

Early studies from Laws (1975) on sex/gender roles and skewed working groups defined academic women as double deviants: (1) they deviate from the gender norms by having a commitment to their career, and (2) they deviate a second time by aspiring to success in a male-dominated field. Kanter (1977) developed a theoretical framework for conceptualising the processes that occur in skewed groups (those with a large proportion of one type, the "dominants", over another, the "tokens"). She concluded that, regardless of the type of minority represented by the tokens, a skewed group will promote the occurrence of three perceptual phenomena associated with tokens: (1) visibility, where tokens have high visibility that creates performance pressures, such as public performance, extension of consequences or fear of retaliation; (2) polarisation, by which the differences between the tokens and the dominants are exaggerated to the extent that they cause boundary heightening and isolation of the token; and, (3) assimilation that involves the use of stereotypes about the token. Kanter maintained that tokenism was only a result of the relative low number of tokens in skewed populations. However, subsequent research has stated that the negative effects of tokenism only occurred when the tokens were of social categories lower than the dominants (Yoder, 1991), for example women doctors or engineers would undergo these negative consequences, while male nurses would not. Acker (1990) introduced the theory of gendered organisations as an attempt to bring together the findings of research on the perpetuation of gender inequality in organisations. And, Britton (2000) developed the epistemology of gendered organisations, advocating for institutional change as the only viable option and thus agreeing with the conclusions presented by Laws (1975) 25 years before. Baumann (2017) presented and analysed narratives and counternarratives of women's (non-) representation in executive leadership. Part of Baumann's analyses include how some narratives simply say that "women need to try harder" and how the business case for parity, which focuses on increased diversity for better team performance, lacks social justice arguments with the narrative "just focusing on educated, middle-class, heterosexual white women". Her study concluded that "the stark absence of women in positions of power cannot be blamed on individual failure. Rather, women face a complex of difficulties that are related and in some cases overlap".

Recent studies analyse gender inequality in specific fields based on evidence of gender imbalances and factors influencing the underrepresentation of women in senior positions and prestige roles (Holmes et al., 2015; Dutt et al., 2016). Such studies are essential to design and implement measures that effectively promote and harness the benefits of gender diversity (Nielsen et al., 2017). Understanding the current state of gender inequity is particularly important in fields historically dominated by men, such as in coastal geoscience and engineering (CGE), as current practices and regulations may still disadvantage women. CGE encompasses professionals working on coastal zone processes, integrating a broad range of expertise across physics, geomorphology, engineering, and sedimentology. To our knowledge, there is no published research on the gender diversity and equity in CGE.

Women in Coastal Geoscience and Engineering (WICGE) is a global network launched on 8th March 2016 at the International Coastal Symposium in Sydney to inspire, support and celebrate women in CGE. Our research builds upon broader studies (Holmes et al., 2008, 2015) and brings unprecedented insights on the nature of gender inequality in CGE, through gathering primary data on women's representation in prestige roles, such as membership in committees of professional societies, editorial boards of journals, and organising committees of international conferences. We also present results from a global survey of male and female perceptions and experiences of gender representation, inequality, and inequity in CGE. We present and discuss our results from a gender perspective, under the theoretical framework of tokenism and gendered organisations. CGE is a markedly masculine field where "token women" are continued to be perceived as "foreigners", and merit is gendered in CGE in the same way as demonstrated for medicine by Santos et al. (2015). We analyse well-known gender phenomena such as the "glass ceiling", the "maternal wall", "gender stereotyping", "boys club" and microagressions. Detailed explanations on the nature of these phenomena and on how they apply to CGE are provided in the corresponding sections. We have chosen a constructive approach where we use our results to identify the types of gender inequality and inequity experienced or observed in CGE, coupled with our analyses of prestige roles to construct seven practical steps to address inequity in CGE. This study constitutes a snapshot of gender equality in CGE in 2016; it is a fundamental step that identifies immediate actions, and provides a baseline from which we can measure future improvements.

\section{Methods}

In this paper, we focus on data for STEM disciplines. We define the term "gender equality" as either "a scenario in which the gender breakdown among roles of a given level or standing is equal" or as "the equal, but not necessarily equitable, provision of resources and opportunities to both men and women" and define gender equity as "the provision of resources and opportunities to both men and women in a way that is not necessarily equal but that addresses the gender inequalities to produce a level playing field". Additionally, we primarily refer to men and women or males and females in this paper but acknowledge that gender is a spectrum rather than binary.

To assess the nature and extent of gender imbalance in the discipline of CGE, we: (1) quantified gender representation in CGE prestige roles: (a) membership and prestige roles (i.e., boards/committees) in nine coastal societies (Supplementary Table S1); (b) 25 journal editorial boards (Supplementary Table 
S2); and (c) organising committees of ten recurring international conferences (Supplementary Table S3); (2) assessed perceptions and experiences of gender representation in CGE using an international survey (Supplementary Table S4); and, (3) used these findings to construct practical suggestions to address this inequality and inequity (Supplementary Table S5).

All data sets analysed are deposited in the Dataverse repository (DOI: $10.7910 / \mathrm{DVN} / \mathrm{F} 1 \mathrm{~B} 2 \mathrm{FS}$ ).

\section{Quantifying gender representation in CGE prestige roles}

Societal membership. We obtained primary data from nine coastal societies from a range of countries in 2016 to evaluate gender representation across the CGE discipline. These are the most prominent coastal societies globally, many of which are associated with a major international conference series. Some of these have members and committee members, and others solely have a committee. Gender information was provided by the societies, with the exception of Coastal Education and Research Foundation (CERF), where gender was manually identified from the list of members (where possible). Supplementary Table S1 provides details of the societies. Society membership ranged from 158 to 3987, and committee size varied between 6 and 42 members. We calculated gender percentages using only those persons for which gender was identifiable.

Journal editorial boards. We identified active journals in the remit of CGE from Scopus, excluding book series. Scopus does not categorise journals by "coastal", thus, journals were defined as being within the remit of CGE by: (1) obtaining journals with the words "coastal", "marine" or "ocean" in the title; (2) retaining only those where the journal description/aims/scope was in the remit of CGE by identifying the following key words in the journal descriptors: marine, coastal, ocean, hydrodynamics, geoscience, sediment, physical oceanography, and/or ocean/ coastal/marine engineering, estuary, beach; then (3) retaining the title only where the journal covered the physical area of interest, i.e., the coast, which we defined here as from the landward limit of wave action, to the edge of the continental shelf. Thus, journals on general marine science were not included. This resulted in 25 journal titles in 2016 (Supplementary Table S2). All of these journals were classified in Scopus as Physical Sciences at the top level, and at the next level, by at least one of: Earth and Planetary Sciences, Engineering, and Environmental Science.

International conference organising committees. We assessed gender representation on the organisational committees of the largest, regular international conferences in the remit of CGE, for which we were able to obtain data on the organising committee. Each of these conferences has "coastal" in the name, or has it as a key theme (Supplementary Table S3). We obtained ratios of males to females in the conferences' committees using the conference websites for the latest conference prior to the end of 2016. We excluded hired administrative staff from conference organising companies.

Assessing perceptions and experiences of gender representation in CGE. Supplementary Table S4 provides a copy of the questionnaire that we used in our CGE survey. Survey content, purpose and associated materials were assessed by the Social Sciences Human Research Ethics Committee at the University of Wollongong. We collected information on demographics, such as gender, years of career experience and sector of work. Subsequent questions were a mix of yes/no/abstain and open answer questions focused on experiences of gender inequality and inequity, and the representation of women in prestige roles in CGE. We solicited suggestions on how perceived gender inequality and inequity could be addressed. The survey launched during the 14th International Coastal Symposium (ICS), held in Sydney, Australia on 6-11 March 2016. We invited conference attendees to fill in a paper-based version of the survey and to deposit it in a ballot box at the venue. This resulted in 37 responses. Following this, and to include non-attendees to the conference, we launched the survey online using Survey Monkey ${ }^{\circledR}$, which ran from September 2016 until January 2017, resulting in an additional 277 responses. We publicised our request to fill the survey via the WICGE website, Twitter, Facebook pages, listservs and email, thus allowing us to obtain results that are not specifically linked to one conference in CGE.

We received 314 survey responses, where eight did not consent for information they provided to be published. Of the 306 remaining respondents, 294 worked or studied in the field of CGE. Of the respondents involved in CGE, 192 (65\%) were female, $99(34 \%)$ were male and $3(\sim 1 \%)$ identified as "other/ blank". Therefore, our analyses focus on contrasting female and male responses $(n=291)$. The majority of these respondents $(73 \% ; n=213)$ are involved in CGE at higher education, universities or research centres, $12 \%(n=36)$ in industry, $11 \%$ $(n=33)$ in government and $3 \%(n=9)$ in other types of organisations. In terms of career level $34 \% \quad(n=100)$ of respondents placed themselves as junior, $41 \%(n=119)$ as midcareer and 25\% $(n=72)$ as senior. Chi-square tests (in SPSS, Supplementary Tables S6 and S7) assessed whether perceptions of female representation and gender bias between male and female respondents were statistically independent of gender $(\alpha=0.05)$. T-test (two-sample assuming unequal variances, $\alpha=0.05$ ) assessed whether the mean number of years working/studying in CGE estimated from male and female respondents was significantly different (Supplementary Tables S8 and S9). We conducted a qualitative thematic analysis in order to identify and report on emergent themes elicited from responses to open-ended questions (Given, 2008). For questions 9 and 12 of the survey (see Supplementary Table S4), answers were grouped into the commonly arising themes listed in the section titled "what is holding back women in CGE?" and Supplementary Table S5, respectively.

\section{Results and discussion}

Our results showed underrepresentation of women in prestige roles in the CGE. The following sections present and analyse our findings, first focusing on the quantitative aspects obtained from our primary data gathering on societies, journals and conferences. We then analyse the reasons behind the underrepresentation using the responses obtained in the survey.

Women represent $30 \%$ of the CGE community. There were no available sources of information to quantify women's representation in CGE prior to this study. Therefore, we used the membership in key professional societies with a coastal focus, as a proxy for women's representation in CGE. We contacted nine key coastal societies worldwide (Supplementary Table S1) requesting information on membership gender representation, obtaining the required data for six of them. Membership size varied from 158 to 3987 and female representation between $15 \%$ and $45 \%$ (Fig. 1), with a mean of $30 \pm 13 \%$; we use this value as our benchmark to assess gender equity in other areas of CGE. This mean value agrees with published figures in related fields; e.g., $33 \%$ of researchers were women in the European Union in 2011 (European Comission, 2016); in science and engineering 28\% of the workforce and $62 \%$ of the academic staff were women in the USA in 2015 (National Science Foundation, 2017). 


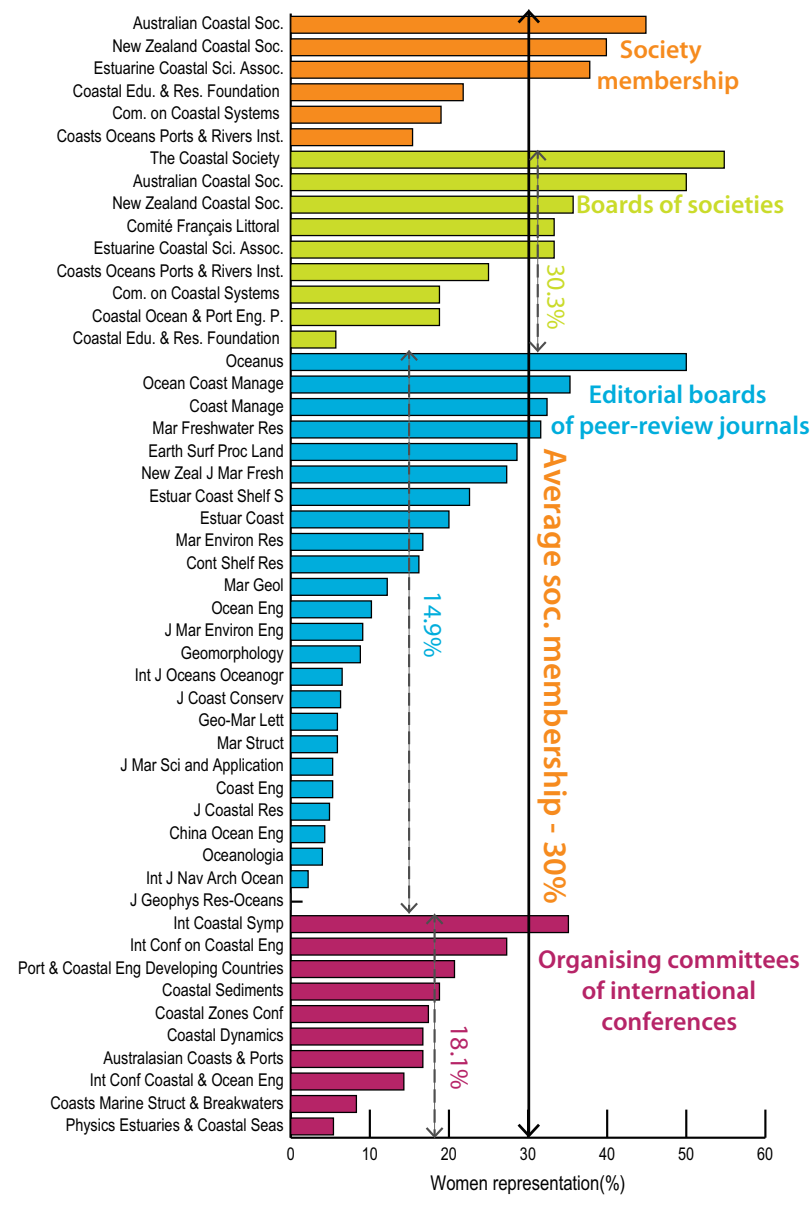

Fig. 1 Female representation in CGE. Percentage of women in membership of key coastal societies (orange); in the board of key coastal societies (green); in editorial boards of peer-review coastal journals (blue); and, in organising committees of international coastal conferences (red). The vertical continuous line represents the average percentage of women in the membership of key coastal societies. Dashed vertical lines represent the average female representation in prestige roles in boards of societies, editorial boards and organising committees for each category

\section{Women's representation rarely matches $30 \%$ of prestige roles in CGE}

Committees of professional societies. Female representation on steering committees of the nine coastal societies was on average $31 \pm 16 \%$, which equals the average female representation in CGE (Fig. 1). However, the proportion of women varied from $6 \%$ (CERF, 3987 members worldwide) to 55\% (Coastal Society, unknown membership size). It is noteworthy that in collaboration with WICGE, CERF has since increased women's representation on their boards to $16 \%$ (July 2017). Five of the nine societies reported at least $30 \%$ women on the steering committee, reflecting the average general society membership.

Journal editorial boards. On average, the representation of females on the editorial boards of the 25 journals was $15 \pm 13 \%$ (Fig. 1). Women represent $30 \%$ or more on only four of the 25 journals, with the range varying from $0 \%$ (Journal of Geophysical Research-Oceans) to 50\% (Oceanus), including just $8 \%$ of Editors in Chief, and $26 \%$ of Associate Editors.

Committees of international conferences. The proportion of women on organising committees of the latest edition (as of 2016) of ten important conferences with focus on CGE held

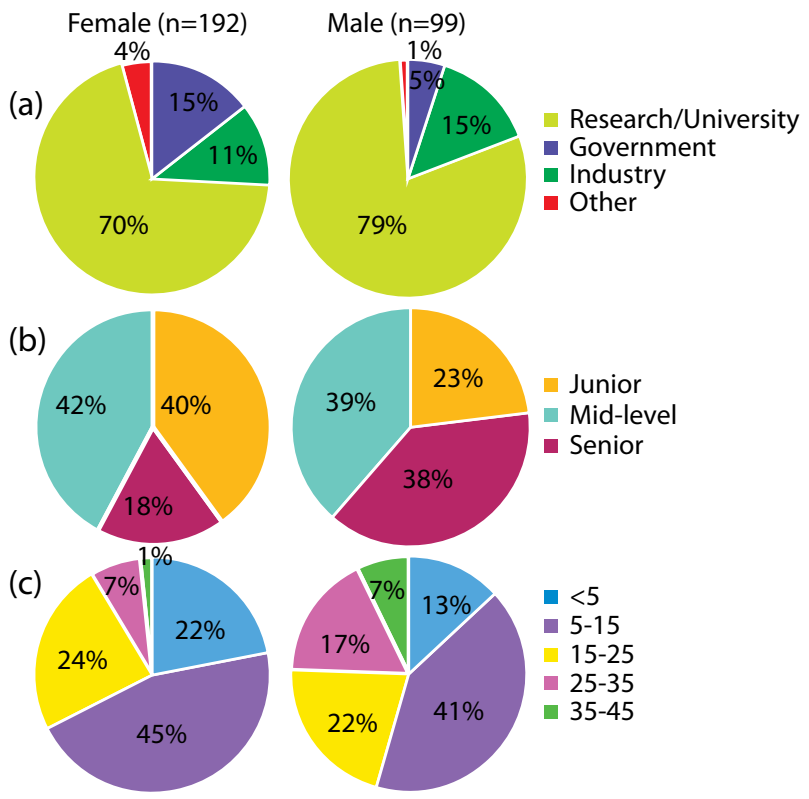

Fig. 2 Demographics of survey respondents. Demographics of survey participants who answered that they work/study in coastal geoscience and engineering ( $n=291)$ : type of employment (a); employment level (b); and, years of experience (c). For $\mathbf{a}$ and $\mathbf{b}$ female counts are $n=192$, while for $\mathbf{c} n$ $=191 ; n=99$ for all male percentages

between 2013 and 2016 was $18 \pm 8.5 \%$ (Fig. 1). The only conference with at least $30 \%$ females in the organising committees was the International Coastal Symposium 2016 (ICS) with 35\% females, followed closely by the International Conference in Coastal Engineering 2016 (ICCE, 27\%); incidentally, these were the only conferences chaired by women. When accounting for chairs and co-chairs, women represented only $22 \%$ (4 out of 18 ). One might think at this point that there are only $18-22 \%$ of women at mid-late career stage available to join these committees. However, the desired $30 \%$ is reached in a few journals and societies, which demonstrates that there are mid-late career women available to participating in committees of international conferences.

Our results show that women's representation in prestige roles only reaches the desired $30 \%$ in committees of professional societies. Female representation in editorial boards and conference organising committees are below the $30 \%$ mark. Paths to prestige roles typically include volunteering, election, or, receiving an invitation to the role. The professional society with the lowest female representation (CERF) is an example of the invitation path, whereas the society with the highest female representation is an example of self-nomination and election in a constitutional process clearly outlined in the website. Similarly, most editorial boards and conference organising committees are invitation-only. Our results show that prestige roles where the process to get involved is clearly outlined and candidates can self-nominate or volunteer for a role, have greater female representation than those where women must receive an invitation. This agrees with other evidence showing that women are less likely to be invited as peerreviewers (Lerback and Hanson, 2017).

Women are underrepresented in prestige roles. Figure 2 shows the differences between female and male respondents in relation to their employment/study sector, career level, and number of years working in CGE. Respondents $(n=291)$ had worked in the field of CGE 12.8 years (standard deviation $=9.3$ ). Female respondents had significantly fewer years working in CGE than 
a

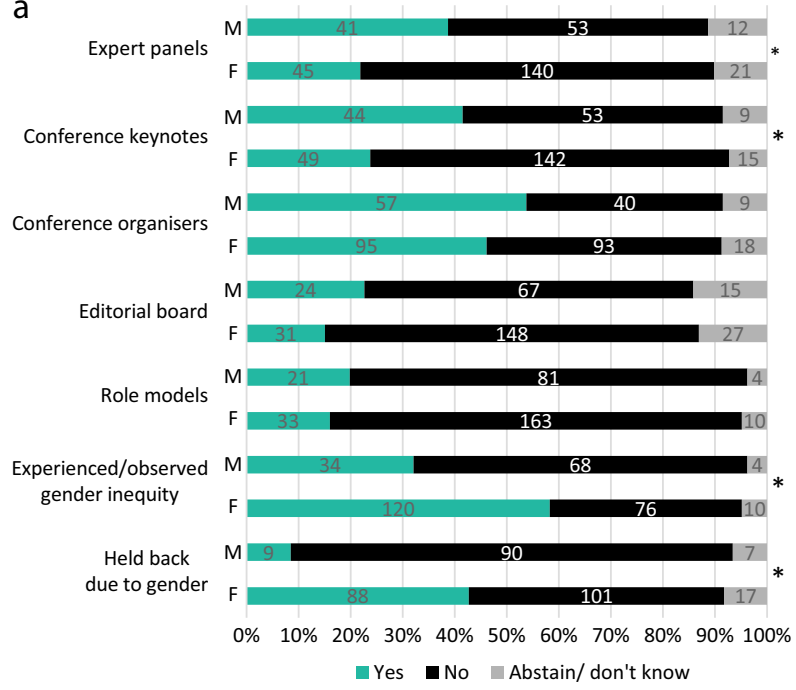

b $\quad \mathrm{n}=0 \quad \begin{array}{lllllll}5 & 10 & 15 & 20 & 25 & 30 & 35\end{array}$

1. Imbalanced representation

1a. Leadership/senior/role models

1b. Few female colleagues

2. Gender stereotyping of females

3. "Glass ceiling" (e.g., lower

imbalance, lack of recognition)

4. "Boys club" (implicit or explicit)

5. Pregnancy and maternity

discrimination

6. Microagressions

7. Harassment

8. Cultural/institutional "norms"

and rules

9. Positive discrimination towards

females

Fig. 3 Survey responses. a Responses to survey questions about how well women are represented in leadership roles; if experienced/ observed gender inequality in CGE; and, if felt held back due to gender. $M=$ male and $\mathrm{F}=$ female. Numbers show raw counts and *indicates statistically different results between $\mathrm{M}$ and $\mathrm{F}$ according to Chi-Square test $(p<0.05)$. b Number of comments in each key category from the survey of respondents working in CGE (total of 171 comments)

male respondents, with mean values of 11.4 years and 15.5 years, respectively $(t=-3.321, p=0.001)$. The percentage of women at junior career stages $(40 \%)$ was almost twice the percentage of men $(23 \%)$. At the senior level, this was reversed with the percentage of women (18\%) being less than half of the percentage of men (38\%). When comparing with the years of experience in CGE, $46 \%$ of men had more than 15 years of experience, while $32 \%$ of the women accounted for the same years of experience. As seniority is typically achieved after years of experience, our data yields that $82 \%$ of the men with more than 15 years of experience were in senior positions, while only $56 \%$ of the women with comparable experience held senior roles. Our results suggest that female participation drops at each step up the career ladder, as commonly reported in STEM. The reasons for this "pipe leak" are complex and likely combine the different experiences and observations identified in the survey. Elsewhere, selection for job positions in geoscience has been identified as an area where women are disadvantaged, due to differences in recommendation letters (Dutt et al., 2016).
What is holding back women in CGE? Both males and females in CGE perceive the existence of gender inequality (Supplementary Table S6). However, the proportion of males who perceive career barriers is significantly lower than the proportion of females in some of the aspects addressed in the survey. For example, $46 \%$ of females $(n=190)$ and $9 \%$ of males $(n=99)$ responded that their careers were held back because of their gender $\left(X^{2}(1)=41.427, p<0.000\right)$. Similarly, $61 \%$ of females $(n$ $=187)$ and $35 \%$ of males $(n=98)$ have reported directly observed or experienced gender inequality $\left(X^{2}(1)=17.775, p<\right.$ $0.000)$. When asked whether respondents believed that gender inequality exists in CGE, a significantly lower proportion of males ( $64 \%$ of $n=99)$ than females ( $88 \%$ of $n=190)$ said yes $\left(X^{2}(1)=\right.$ $23.574, p<0.000)$. Responses show that significantly more females $(51 \%)$ than males $(24 \%)$ provided examples of their experiences or direct observations of gender inequality and inequity in CGE $\left(X^{2}(1)=19.268, p<0.0001\right)$. However, when asked to provide practical suggestions on how to reduce gender bias $52 \%$ of females and $39 \%$ of males responded $\left(X^{2}(1)=3.879\right.$, $p=0.049$ ). Observations and experiences reported by men and women were categorised into nine common types (Fig. 3). Overall, results strongly suggest that gender inequality has a detrimental impact on women working in CGE.

The CGE community clearly acknowledges the lack of female representation in prestige roles with $82 \%$ of female and $79 \%$ of male $\left(X^{2}(1)=0.599, p=0.439\right)$ respondents believing that there are not enough female role models in CGE (Fig. 3a). One respondent stated: "Never worked for a female boss. rarely [sic] worked with female peers" (Female, 20 years-experience, university/research). Overall, the majority of males and females believe women are not well represented in CGE prestige roles, such as giving keynotes at conferences (73\% of females; $55 \%$ of males, $\left.X^{2}(1)=9.431, p=0.002\right)$, membership on expert panels (75\% of females; $56 \%$ of males, $X^{2}(1)=9.716, p=0.002$ ), and journal editorial board members ( $82 \%$ of females; $75 \%$ of males, $\left.X^{2}(1)=1.810, p=0.178\right)$. The only exception is female representation on conference organising committees, which most male (58\%) and female $(51 \%)$ respondents indicate a fair representation $\left(X^{2}(1)=1.104, p=0.293\right)$. This perception does not reflect our data, which indicate that women's representation on organising committees is $18 \%$ on average (Fig. 1). A possible reason for the mismatch is that a number of the survey responses (12\%) were collected at the International Coastal Symposium 2016, which had 35\% women in the committee, including the conference chair. All other responses were not linked to this conference but were collected afterwards.

The "glass ceiling" metaphor describes how the career advancement of minorities, such as women, is blocked by a barrier which is invisible to the individual, who is passed over for career advancements in favour of male colleagues (Morrison et al., 1987; Tang, 1997). While many institutions have formal policies that commit to a fair chance, informal norms and customs in work places and disciplines may undermine these policies to impose the glass ceiling (De Welde and Laursen, 2011). This is demonstrated by survey comments such as "many examples I've seen (\& I'm male!) (...) females only been selected for short listing to make it look like it is gender balanced, with no intention of them being appointed" (male, 21 years-experience, university/research), "[Women] Having to be $10 \times$ [sic] as good and productive to even be equated with men in the old boys network" (female, 32 years-experience, university/research).

Gender stereotyping was among the most common manifestation of inequality in CGE. Stereotyping of women in STEM as not being as competent (or being incompetent), and not being taken seriously, is a key theme (National Science Foundation, 2017). Responses indicate stereotyping is common in fieldwork, limiting 
participation of women, and discriminating women's ability to undertake fieldwork tasks. For example "I am not included in tasks that are considered more male oriented like heavy lifting or (...) deploying instruments. (...) I keep getting passed over for the nearest male (whom is not closer than me)" (female, 6 yearsexperience, government). For many CGE professions, fieldwork is integral to career progression as it enables gathering of primary environmental data, and development of skills and collaboration networks, which in turn increase productivity in terms of funding and publishing success.

The "boys club" refers to a general culture favouring men, such as in recruitment and collaboration (including the aforementioned fieldwork). Previous research (De Welde and Laursen, 2011) states that males are generally invited to informal activities such as social events, while women are not automatically granted the "buddy status". This excludes women from discussions and collaborations, an issue that emerged in the survey: "Male colleagues talking to one another but excluding female colleagues" (female, 10 years-experience, university/research) and "Not being invited to join experiments or groups of people" (female, 24 years-experience, university/research). This does not create an attractive working environment for females, as demonstrated by this survey respondent: "During a job interview, the lead engineer (male) was explaining how they have the "boys club"here at the office. They did offer me the job, but I didn't want to work in that type of environment" (female, 4 years-experience, other).

The "maternal wall" results from expectations that a woman's job performance is affected by her having children (Williams, 2004; Williams and Ceci, 2012). Nineteen comments from the survey related to discrimination due to pregnancy and maternity leave, including recruitment biases. This survey respondent demonstrates this: "When applying for a new job, my (female, childless) supervisor told the phone interviewer that I might not be a good choice because I was planning to start a family. (I was visibly pregnant at the time.)" (female, 17 years-experience, government). One respondent said, "My supervisor aked [sic] me to abandon my $\mathrm{PhD}$ when I become pregnant" (female, 8 yearsexperience, university/research). Our survey showed how pregnancy is seen as a major risk in pursuing an academic career with one respondent stating: "I recently made the awful decision to have an abortion (...) I knew that I would be unable to get back into academia again if it coincided with a period of unemployment, and that I wouldn't be competitive for jobs if I was pregnant, and I would be risking my career" (female, 8 yearsexperience, university/research). The combination of the maternal wall and the glass ceiling often obliges women to work harder to prove themselves (Williams, 2004). There is a strong feeling that females returning from maternity leave sacrifice progress in their careers and lack recognition, are promoted slowly, and are less able to be productive and lead or collaborate on projects.

The final key manifestation of gender inequality arising from the survey is micro-aggressions and harassment. Microaggressions are derogative comments or actions that are indirect, subtle or unintentional (Serio, 2016), and were mentioned 19 times in the survey comments. Examples from the survey include remarks such as "where is the glitter in your handwriting" (female, 4 years-experience, university/research). In addition, being overlooked and ignored in favour of male colleagues was a key issue, e.g., "Getting my first big grant and employing a male post doc-our project partners treated him as the boss" (female, 20 years-experience, university/research), and comments about looks, such as "comments on my "pretty face" being an asset for attracting clients" (female, 32 years-experience, university/ research). Micro-aggressions have received little research attention, but elsewhere there is evidence they may be one of the major contributors to the lack of diversity in science (Serio, 2016), and a substantial barrier to STEM professions for minority groups affected by intersectionality of gender identity issues (Yoder and Mattheis, 2016).

Many of the comments that we received in our survey referred to fieldwork. For example, these may arise from cultural and institutional norms and rules that can prevent women from doing fieldwork completely, such as "I was banned from a fieldtrip to collect information at one of [my] Ph.D research sites in Saudi Arabia" (female, 15 years-experience, university/research). One survey respondent commented that "Sometimes women are "advised" to avoid field works [sic], for security reasons (or they are considered weak, or we are threatened [sic] by rape for being with a lot of men)" (female, 8 years-experience, university/ research). Comments also show that harassment while on fieldwork is an issue for women, e.g., "I've twice experienced harrassment [sic] on fieldwork expeditions" (female, 8 yearsexperience, university/research).

Interestingly, four of our male respondents referred to the "Positive discrimination towards females" as a cause for gender inequality in CGE. While two of them referred to this matter as possibly promoting unsuitable candidates, "it is dangerous and counter-productive to promote someone to a position the [sic] are not capable of" (male, 10 years-experience, industry). The other two mentioned a perceived discrimination against males "Almost all scholarships specify that women applying is advantageous and I've really felt that I have to be significantly better as a candidate than I would as a woman" (male, 3 yearsexperience, university/research).

In summary, our survey shows that $64 \%$ of males and $88 \%$ of females believe that gender inequality and inequity exist in CGE $\left(X^{2}\right.$ $(1)=23.574, p<0.000)$; with $61 \%$ of females directly experienced or observed gender inequality and inequity in the discipline, compared to $35 \%$ of males $\left(X^{2}(1)=17.775, p<0.000\right)$. This may reflect that males experience less direct discrimination, or differences in the way female and male respondents identify or recognise gender inequality. It is noteworthy that $81 \%$ of respondents thought that there were not enough female role models in CGE, remarkably there were no significant differences between male $(79 \%)$ and female $(82 \%)$ respondents $\left(X^{2}(1)=0.599, p=0.439\right)$.

Overall, our results consolidate the perception of CGE as a field where merit is gendered and, therefore, we can apply the theoretical frameworks developed by Yoder (1991), Santos et al. (2015) and Baumann (2017), among others. Women in CGE are perceived as tokens of lower social category (sensu Acker, 1990) and, therefore, undergo the consequences of tokenism as described by Kanter (1977), including greater visibility and performance pressures, isolation due to polarisation, and stereotyping because of assimilation. The gendered organisation of CGE leads to women often being overlooked in favour of men; as previously stated by Baumann (2017), the solution to being overlooked is an institutional change and does not only rely on women having to try harder. One clear example arising from our data (Fig. 1) is that when women are given the chance, as in the case of some of the societies studied, they self-nominate for prestige roles and thus fair representation of women becomes achievable. Our results show that we need to act to reduce malebiased "rules and behaviours", to enable retention and career progression of women in CGE.

\section{Conclusions: Seven steps towards achieving gender equity in CGE}

While gender imbalance in STEM has improved, it is not a "selfcorrecting phenomenon" (European Comission, 2013). It will not adjust by changing the behaviour of the women within the field; it needs changes to structure and policy. Gender equity guarantees 
women the same opportunities as men in benefiting from the fruits of research, contributing to society, earning a living, and choosing a fulfilling profession (Huyer, 2015). A number of approaches can be taken to promote an equitable and diverse workplace (National Academy of Sciences, 2007). However, we need to identify immediate practical steps to reduce this lack of equality. Suggestions from the survey respondents (Supplementary Table S5) include the following practical steps to address gender inequality and inequity:

1. Advocate for more women in prestige roles: Collaborating with more women, ensuring a fair representation of women as keynote speakers at conferences, or affirmative action hiring will increase female representation in prestige roles. Another action is involving more women in international collaborations (including grant proposals) to increase research performance and publication productivity (Cole and Zuckerman, 1984; Kyvik and Teigen, 1996; Bentley, 2011) and break the "boys club" habit. For example the AGU hired more female editors to assist with reducing gender bias when recruiting referees (Lerback and Hanson, 2017). Another step is limiting invitation-only pathways into prestige roles that lack transparency and are subject to bias.

2. Promote high-achieving females: Make females more visible as role models, selecting them for prestige roles (Nature Editors, 2013), and recognise their achievements through initiatives such as awards (Rossiter, 1993). One of our survey respondents stated: "I think there are many role models out there, but not enough are publicised the way males are. (...) Publicise more female role models (through social media and journals and magazines)" (female, 5 years-experience, university/research).

3. Awareness of gender bias: Males and females alike have gender biases for hiring, salary, and mentoring (MossRacusin et al., 2012). Personnel in charge of hiring new staff should consciously reflect on this when assessing applicants and undertake actions to reduce this. One of our male respondents argued, "as a guy this sort of thing really makes me more conscious of the issues facing women in engineering and makes me think about how I can change my own behaviour for the better" (male, 5 years-experience, university/research).

4. Speak up: All of us should speak up (Serio, 2016) when we see an all-male panel, conference, editorial board, publication or grant. This applies to both men and women in CGE, "(sadly) men might be more inclined to listen when a fellow male engineer calls them out on their sexism" (male, 5 yearsexperience, university/research). Based on our own experience, organising committees are glad to be contacted about the potential under-representation of women, and willing to create a diverse and representative event.

5. Better support for return to work: Better support when returning from maternity leave and flexible work conditions is important, as having young children directly affects the productivity of females (Long et al., 1993; Kyvik and Teigen, 1996; Williams and Ceci, 2012). Better performance measurements and flexibility in relation to hiring, publication and promotion would ensure that women (and men) who interrupt their career during their child-bearing years do not jeopardise their future career (National Academy of Sciences, 2007; Williams and Ceci, 2012). Men would also benefit from schemes encouraging "maternity/paternity leave sharing standard" (male, 12 years-experience, university/research).

6. Redefine success: Encouraging diversity by being respectful that "success" means different things to different people, e.g., it could be having a secure position and contributing to the field while working flexible hours and enjoying life beyond work, as opposed to being a "star performer" based on often quantitative workplace and disciplinary criteria (De Welde and Laursen, 2011). Many of our respondents emphasised breaking down stereotypes: "trying to break the stereotype of "females have kids, their brains go mushy and they are not focused on their careers anymore" "(female, 10 yearsexperience, other).

7. Encourage more women to enter the discipline at a young age: Many of our respondents emphasised the idea of needing to encourage more young females to enter the discipline. However, our data and existing publications (e.g., Huyer, 2015; Nielsen et al., 2017) suggest that more effort is needed in retaining and promoting women to prevent pipeline loss in CGE.

We believe that CGE can achieve these practical steps by ensuring the following three key objectives: (1) unbiased education at all levels; (2) transparency in hiring, promotion processes and pathways to prestige roles; and, (3) establishing mentoring programs for females in CGE. We acknowledge that some of the seven steps listed above can be successfully implemented straight away (steps 1-4); steps 5 and 6 need institutional engagement; and, step 7 is a decadal endeavour. However, all the proposed steps require action of the CGE community and can start immediately. The Women in Coastal Geoscience and Engineering (WICGE) network is already successfully implementing some of these steps by influencing conference organisers to include keynote talks from female researchers and societies to improve gender balance. It is crucial that the wider community becomes aware of the extent of inequality, so everyone can undertake practical steps (such as the above) to remove gender inequalities in CGE and STEM in general.

Received: 24 January 2018 Accepted: 11 July 2018

Published online: 04 September 2018

\section{References}

Acker J (1990) Hierarchies, jobs, bodies: A theory of gendered organizations. Gend Soc 4(2):139-158

Baumann H (2017) Stories of women at the top: narratives and counternarratives of women's (non-)representation in executive leadership. Palgrave Commun 3:17009. https://doi.org/10.1057/palcomms.2017.9

Bentley P (2011) Gender differences and factors affecting publication productivity among Australian university academics. J Sociol 48(1):85-103. https://doi. org/10.1177/1440783311411958

Britton DM (2000) The epistemology of the gendered organisation. Gend Soc 14 (3):418-434

Cole J, Zuckerman H (1984) The productivity puzzle: Persistence and change in patterns in publication of men and women scientists. In: Advances in motivation and achievement. vol. 2. Greenwich, CT: JAI Press, pp. 217-256

De Welde K, Laursen S (2011) The glass obstacle course: Informal and formal barriers for women Ph.D. students in STEM fields. Int J Gend, Sci Technol 3 (3):571-595

Dutt K, Pfaff DL, Bernstein AF, Dillard JS, Block CJ (2016) Gender differences in recommendation letters for postdoctoral fellowships in geoscience. Nat Geosci 9(11):805-808. https://doi.org/10.1038/ngeo2819

European Comission (2013) She figures 2012. Gender in research and innovation: Statistics and indicators. https://doi.org/10.2777/38520.

European Comission (2016) She Figures 2015. 224pp https://ec.europa.eu/research/ swafs/index.cfm?pg=library\&lib=gender_equality. https://doi.org/10.2777/ 38520

Given L (2008) The SAGE Encyclopedia of Qualitative Research Methods. SAGE Publications, Thousand Oaks California, 10.4135/9781412963909

Holmes MA, O'Connell SB, Dutt K (2015) Women in the geosciences: practical, positive practices toward parity. John Wiley \& Sons: AGU Special Publication Series, pp 180https://doi.org/10.1002/9781119067573

Holmes MA, O'Connell S, Frey C, Ongley L (2008) Gender imbalance in US geoscience academia. Nat Geosci 1(3):148-148. https://doi.org/10.1038/ ngeo 148 
Holter ØG (2014) What's in it for Men? Men Masc 17(5):515-548. https://doi.org/ $10.1177 / 1097184 X 14558237$

Huyer S (2015) Is the gender gap narrowing in science and engineering. UNESCO Global Science Report: Towards 2030

Kanter RM (1977) Some effects of proportions on group life: Skewed sex ratios and responses to token women. Am J Sociol 82(5):965-990

Kyvik S, Teigen M (1996) Child care, research collaboration, and gender differences in scientific productivity. Sci, Technol, Human Values 21(1):54-71

Laws JL (1975) The psychology of tokenism: An analysis. Sex Roles 1(1):51-67. https://doi.org/10.1007/BF00287213

Lerback J, Hanson B (2017) Journals invite too few women to referee. Nat News 541(7638):455. https://doi.org/10.1038/541455a

Long JS, Allison PD, McGinnis R (1993) Rank advancement in academic careers: Sex differences and the effects of productivity. Am Sociol Rev 58(5):703-722. https://doi.org/10.2307/2096282

Miller DI, Wai J (2015) The bachelor's to Ph.D. STEM pipeline no longer leaks more women than men: a 30-year analysis. Front Psychol 6:37. https://doi. org/10.3389/fpsyg.2015.00037

Morrison AJ, White RP, Van Velsor E (1987) Breaking the glass ceiling: Can women reach the top of America's largest corporations? Perseus Publishing, Cambridge, MA

Moss-Racusin CA, Dovidio JF, Brescoll VL, Graham MJ, Handelsman J (2012) Science faculty's subtle gender biases favor male students. Proc Natl Acad Sci 109(41):16474-16479. https://doi.org/10.1073/pnas.1211286109

National Academy of Sciences (2007) Beyond bias and barriers: Fulfilling the potential of women in academic science and engineering. The National Academies Press: National Academy of Sciences, National Academy of Engineering, Institute of Medicine, Washington, DC, $346 \mathrm{pp}$. https://doi.org/ doi: $10.17226 / 11741$

National Science Foundation (2017) Women, minorities, and persons with disabilities in science and engineering: 2017 digest. National Science Foundation. Special Report NSF 17-310, pp. 1-21 https://doi.org/Special Report NSF $17-310$

Nature Editors (2013) Science for all. Nat News 495(7439):5. https://doi.org/ $10.1038 / 495005$ a

Nature Editors (2017) Gender imbalance in science journals is still pervasive. Nat News 541(7638):435. https://doi.org/10.1038/541435b

Nielsen MW, Alegria S, Börjeson L, Etzkowitz H, Falk-Krzesinski HJ, Joshi A, Leahey E, Smith-Doerr L, Woolley AW, Schiebinger L (2017) Opinion: Gender diversity leads to better science. Proc Natl Acad Sci 114 (8):1740-1742. https://doi.org/10.1073/pnas.1700616114

Rossiter MW (1993) The Matthew Matilda effect in science. Social Stud Sci 23 (2):325-341

Santos MH, Amâncio L, Roux P (2015) Numbers do not tell the whole story: Gender and medicine in Portugal. Women's Stud Int Forum 53:73-82. https://doi.org/10.1016/j.wsif.2015.08.005

Serio T (2016) Speak up about subtle sexism in science. Nat News 532(7600):415. https://doi.org/10.1038/532415a

Talbot M (1910) Eminence of women in science. Science 32(833):866. https://doi. org/10.1126/science.32.833.866

Tang J (1997) The glass ceiling in science and engineering. J Socio-Econ 26 (4):383-406. https://doi.org/10.1016/S1053-5357(97)90003-2

Williams JC (2004) Hitting the maternal wall. Academe 90(6):16-20. https://doi. org/10.2307/40252700

Williams WM, Ceci SJ (2012) When scientists choose motherhood: a single factor goes a long way in explaining the dearth of women in math-intensive fields. How can we address it? Am Sci 100(2):138-145. https://doi.org/10.1511/ 2011.89.106
Yoder JB, Mattheis A (2016) Queer in STEM: Workplace experiences reported in a National Survey of LGBTQA individuals in science, technology, engineering, and mathematics careers. J Homosex 63(1):1-27. https://doi.org/10.1080/ 00918369.2015.1078632

Yoder JD (1991) Rethinking tokenism: looking beyond numbers. Gend Soc 5:178-192

\section{Data availability}

The data sets analysed during the current study are available in the Dataverse repository: https://doi.org/10.7910/DVN/F1B2FS.

\section{Acknowledgements}

We thank Lin Wang (University of Sydney) for assistance in data compilation, and to the coastal societies who were supportive of the process and provided data. We are grateful to all survey respondents for taking the time to write about their experiences and suggestions. Ethics number 2016/052, approved by the University of Wollongong Social Sciences Human Research Ethics Committee.

\section{Author contributions}

AV-C and SLG had key roles in developing the project, paper writing and manuscript submission. SLG led data collation. SH led designing and implementing the survey. LSE led the statistical analyses. All authors contributed to project design, gathering primary data of representation of women in prestige roles, discussion of data analysis and writing this paper.

\section{Additional information}

The online version of this article (https://doi.org/10.1057/s41599-018-0154-0) contains supplementary material, which is available to authorised users.

Competing interests: The authors declare no competing interests.

Reprints and permission information is available online at http://www.nature.com/ reprints

Publisher's note: Springer Nature remains neutral with regard to jurisdictional claims in published maps and institutional affiliations.

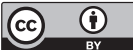

Open Access This article is licensed under a Creative Commons Attribution 4.0 International License, which permits use, sharing, adaptation, distribution and reproduction in any medium or format, as long as you give appropriate credit to the original author(s) and the source, provide a link to the Creative Commons license, and indicate if changes were made. The images or other third party material in this article are included in the article's Creative Commons license, unless indicated otherwise in a credit line to the material. If material is not included in the article's Creative Commons license and your intended use is not permitted by statutory regulation or exceeds the permitted use, you will need to obtain permission directly from the copyright holder. To view a copy of this license, visit http://creativecommons.org/ licenses/by/4.0/.

(c) The Author(s) 2018

Ana Vila-Concejo (1) ', Shari L. Gallop², Sarah M. Hamylton ${ }^{3}$, Luciana S. Esteves ${ }^{4}$, Karin R. Bryan ${ }^{5}$, Irene Delgado-Fernandez ${ }^{6}$, Emilia Guisado-Pintado ${ }^{7}$, Siddhi Joshi ${ }^{8}$, Graziela Miot da Silva9 Amaia Ruiz de Alegria-Arzaburu ${ }^{10}$, Hannah E. Power ${ }^{11}$, Nadia Senechal ${ }^{12}$ \& Kristen Splinter $^{13}$

${ }^{1}$ Geocoastal Research Group, School of Geosciences, The University of Sydney, F09, Sydney, NSW 2006, Australia. ${ }^{2}$ Department of Environmental Sciences, 12 Wally's Walk, Macquarie University, Sydney, NSW 2109, Australia. ${ }^{3}$ School of Earth and Environmental Sciences, University of Wollongong, Wollongong, NSW 2522, Australia. ${ }^{4}$ Faculty of Science \& Technology, Bournemouth University, Poole, Dorset BH12 5BB, UK. ${ }^{5}$ School of Science, University of Waikato, PB3105, Hamilton 3240, New Zealand. ${ }^{6}$ Geography Department, Edge Hill University, Ormskirk, Lancashire L39 4QP, UK. ${ }^{7}$ Physical Geography and Regional Geographic Analysis Department, University of Seville, c/Maria de Padilla s/n 41004, Seville, Spain. ${ }^{8}$ Geography, School of Geography and Archaeology, Ryan Institute for Environment, Marine and Energy, National University of Ireland Galway, University Road, Galway H91 TK33, Ireland. ${ }^{9}$ College of Science and Engineering, Flinders University, Adelaide, SA 5042, Australia. ${ }^{10}$ Institute of 
Oceanographic Research, University of Baja California, Ensenada, Baja California 22860, Mexico. ${ }^{11}$ School of Environmental and Life Sciences, University of Newcastle, Callaghan, NSW 2308, Australia. ${ }^{12}$ University of Bordeaux, UMR EPOC CNRS, Talence, France. ${ }^{13}$ Water Research Laboratory, School of Civil and Environmental Engineering, UNSW Sydney, Manly Vale, Sydney, NSW 2093, Australia. 